\title{
Droplet spectra and high-speed wind tunnel evaluation of air induction nozzles
}

\author{
Qing TANG ${ }^{1,2,3}$, Liping CHEN $(\bowtie)^{1,2,3}$, Ruirui ZHANG ${ }^{1,2,3}$, Min XU ${ }^{1,2,3}$, Gang XU ${ }^{1,2,3}$, Tongchuan YI ${ }^{1,2,3}$, \\ Bin ZHANG ${ }^{1,2,3}$
}

\author{
1 Beijing Research Center of Intelligent Equipment for Agriculture, Beijing Academy of Agriculture and Forestry Sciences, \\ Beijing 100097, China \\ 2 National Research Center of Intelligent Equipment for Agriculture, Beijing 100097, China \\ 3 Beijing Key Laboratory of Intelligent Equipment Technology for Agriculture, Beijing 100097, China
}

\begin{abstract}
A series of air induction nozzles were tested in a high-speed wind tunnel. Droplet size spectra were measured for four air induction nozzles (IDK-120-01, IDK-120-02, IDK-120-03 and IDK-120-04) each at three spray pressures $(0.3,0.4$ and $0.5 \mathrm{MPa})$ and seven different air velocities $(121.7,153.4,185.5,218.4,253.5,277.5$ and $\left.305.5 \mathrm{~km} \cdot \mathrm{h}^{-1}\right)$. The measurement distance $(0.15,0.25$ and $0.35 \mathrm{~m}$ ) from the nozzle orifice was found to be important for the atomization of the droplets. The response surface method was used to analyze the experimental data. The results indicated that $D \mathrm{v}_{0.1}$ and $D \mathrm{v}_{0.5}$ of the droplets decreased quasi-linearly with increased wind speed, while $D \mathrm{v}_{0.9}$ was affected by the quadratic of wind speed. $D \mathrm{v}_{0.1}$, $D \mathrm{v}_{0.5}$ and $D \mathrm{v}_{0.9}$ of the droplets were all proportional to the orifice size, and were not markedly influenced by the spray pressure. The percentage of the spray volume consisting of droplets with a diameter below $100 \mu \mathrm{m}(\%<100 \mu \mathrm{m})$ was found to be quadratically related to wind speed, and was not markedly influenced by the spray pressure and orifice size. However, the effect of the orifice size on the $\%<$ $200 \mu \mathrm{m}$ could not be ignored.
\end{abstract}

Keywords air induction nozzle, wind tunnel, aerial spray, droplet size spectra

\section{Introduction}

With its low cost and high efficient performance, aerial spraying has become the most common method for pesticide application in large fields ${ }^{[1]}$. However, aerial spraying can easily cause droplet drift and off-target damage to the environment or public health ${ }^{[2,3]}$. The cross wind speed and spray droplet size have long been

Received June 7, 2017; accepted August 18, 2017

Correspondence: chenlp@nercita.org.cn considered as two of the dominant factors influencing drift $^{[4-6]}$. When the great losses of small droplets were taken into consideration, the droplet size distribution was found more important than average droplet size after the original publication of ASAE S572 ${ }^{[7,8]}$. Aerial spray droplet size and spectra were influenced by many parameters such as nozzle type, size, spray pressure, and so on ${ }^{[9,10]}$.

However, the initial droplet size distribution in aerial spray is still very hard and expensive to obtain directly in the aircraft. It is also hard to make a ground test, because the application speed of the airplane is very high and the air shear will smash the droplets immediately when they come out of the nozzle ${ }^{[11]}$. Thus, wind tunnels have been used to simulate a real flight-speed environment to estimate the air shear effect on the droplets generated by the aerial spray nozzles. Kirk and Hewitt studied the influence of wind speed, spray pressure, orientation angle of the nozzle and nozzle orifice size on aerial spray droplet size spectra in various wind tunnel experiments ${ }^{[8,12]}$. These four parameters were used to assess the spray droplet size spectra of the flat fan nozzles. The response surface method has also been used to design experiments.

Subsequently, a series of experimental studies of the performance of the flat fan nozzles were made by Frits et al. in high-speed wind tunnels at USDA-ARS, University of Queensland and University of NebraskaLincoln $^{[13-15]}$. The measurement systems had been upgraded with more modern technology. A central composite design response surface method was used to design the experiments instead of the Box-Behnken design method. The current USDA-ARS aerial spray nozzle atomization models have been updated through all of these efforts $^{[16]}$.

In addition to flat fan nozzles, which have been studied carefully under all operating conditions, air induction nozzles have been recommended over the past 20 years by 
some nozzle manufacturers and researchers to reduce spray drift by generating droplets filled with air. Its performance has been widely studied under low speed conditions ${ }^{[9,17-22]}$. However, the application efficiency of this kind of nozzle still remains controversial ${ }^{[23,24]}$.

So far, few experiments have examined the performance of this kind of nozzle under high speed conditions. Commonly it is believed that the strong air shear under high speed conditions will break the bubbles generated by the air induction nozzles rendering them useless. However, Tang et al. ${ }^{[25]}$ found that under high speed conditions, air induction nozzles perform better than flat fan nozzles at the same flow rate. They have a lower RS, higher $D \mathrm{v}_{0.5}$, and are insensitive to spray pressure changes. In this study, a series of air induction nozzles were tested in a newly designed high-speed wind tunnel at National Research Center of Intelligent Equipment for Agriculture (NRCIEA). The spray droplets were measured with varying orifice size, spray pressure and wind speed. A response surface method was used to analyze the experimental data. A simplification of the fitted equations of the atomization parameters was used to find the factors influencing atomization and spray droplet size from spray nozzles on agricultural aircraft.

\section{Materials and methods}

The nozzle test was conducted in the IEA-I high-speed wind tunnel at NRCIEA, Beijing, China. The spray pressure and flow rate of the nozzles were adjustable with a spray control system. Droplet size and spectra measurements were made using a Malvern Spraytec laser diffraction instrument (Malvern Instruments, Malvern, UK) and its diameter distributions were analyzed by the software of Malvern Corporation.

\subsection{Test design}

The IDK nozzles tested in this paper were produced by Lechler GmbH (Ulmer Street 128, D-72555 Metzingen, Baden-Württemberg, Germany). These kinds of air induction nozzles have a droplet generation principle based on the Venturi effect ${ }^{[20]}$. The nozzles were mounted on the tube of the spray control system, and the orifice was about $0.1 \mathrm{~m}$ away from the exit of the wind tunnel. The temperature was $20^{\circ} \mathrm{C}$, and the relative humidity was $30 \%$ during the experiment. Tap water was used as the test medium.

$D \mathrm{v}_{0.1}, D \mathrm{v}_{0.5}, D \mathrm{v}_{0.9}, \mathrm{RS}, \%<100 \mu \mathrm{m}$ and $\%<200 \mu \mathrm{m}$ of the droplets were analyzed. The atomization parameters were defined as follows:

$D \mathrm{v}_{0.1}=$ droplet size such that $10 \%$ of the spray volume is droplets smaller than $D \mathrm{v}_{0.1}$.

$D \mathrm{v}_{0.5}=$ droplet size such that $50 \%$ of the spray volume is droplets smaller than $D \mathrm{v}_{0.5}$.
$D \mathrm{v}_{0.9}=$ droplet size such that $90 \%$ of the spray volume is droplets smaller than $D \mathrm{v}_{0.9}$.

$\mathrm{RS}=$ relative span of the droplets, which is defined by the formula $\left(D \mathrm{v}_{0.9}-D \mathrm{v}_{0.1}\right) / D \mathrm{v}_{0.5}$. It is a measure of the range of droplet size spectrum in the spray, with smaller numbers indicating a narrower range of droplet sizes, accounting for the mid $80 \%$ of the spray volume.

$\%<100 \mu \mathrm{m}=$ percentage of the spray volume contained in droplets with a diameter below $100 \mu \mathrm{m}$.

$\%<200 \mu \mathrm{m}=$ percentage of the spray volume contained in droplets with a diameter below $200 \mu \mathrm{m}$.

Each case was replicated three times and each acquisition time lasted $50 \mathrm{~s}$. The final result of the case was the mean value of the three measurements. The droplet size spectra measured by the Malvern Spraytec laser diffraction instrument were carefully analyzed. $D \mathrm{v}_{0.5}$ and RS of the droplets were extracted from the experimental data.

The test parameters are listed below:

(1) The air induction nozzle types IDK-120-01, IDK120-02, IDK-120-03 and IDK-120-04 (Fig. 1) were tested.

(2) The distances from the nozzle orifice to the measurement point were $0.15,0.25$ and $0.35 \mathrm{~m}$.

(3) The wind speeds were 121.7, 153.4, 185.5, 218.4, $253.5,277.5$ and $305.5 \mathrm{~km} \cdot \mathrm{h}^{-1}$.

(4) The flow rate of the nozzles depends on the spray pressure and their types, as shown in Table 1.

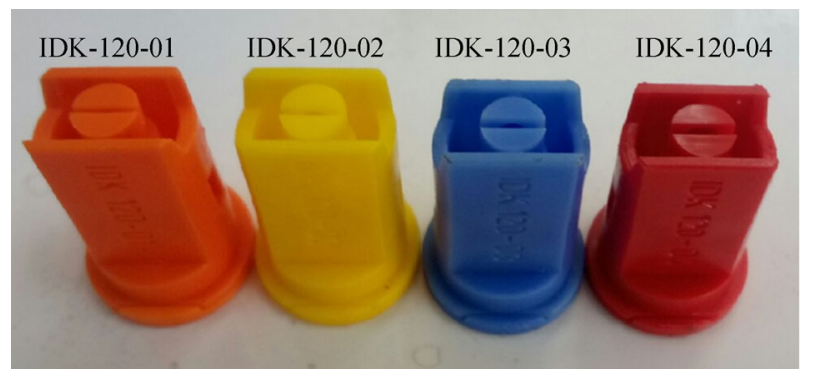

Fig. 1 The IDK nozzles with different orifice sizes

Table 1 The flow rate of the nozzles at different spray pressures

\begin{tabular}{lcc}
\hline Nozzle type & Spray pressure/MPa & Flow rate $/\left(\mathrm{L} \cdot \mathrm{min}^{-1}\right)$ \\
\hline IDK-120-01 & 0.3 & 0.39 \\
& 0.4 & 0.45 \\
IDK-120-02 & 0.5 & 0.51 \\
& 0.3 & 0.80 \\
& 0.4 & 0.92 \\
IDK-120-03 & 0.5 & 1.03 \\
& 0.3 & 1.19 \\
& 0.4 & 1.37 \\
IDK-120-04 & 0.5 & 1.53 \\
& 0.3 & 1.58 \\
& 0.4 & 1.82 \\
& 0.5 & 2.04 \\
\hline
\end{tabular}




\subsection{Wind tunnel facility}

The IEA-I high-speed wind tunnel, built in 2015, at the aerial spray laboratory of NRCIEA, was used. It was a blow down wind tunnel with a maximum wind speed of $350 \mathrm{~km} \cdot \mathrm{h}^{-1}$, which could cover the highest speed of fixedwing agricultural aircraft. This tunnel contained a carefully designed setting chamber with honeycomb and screen meshes, which could greatly improve the flow quality of the test section. A detailed structure diagram of the IEA-I high-speed wind tunnel is given in Fig. 2.

The operational conditions of the IEA-I high-speed wind tunnel are listed in Table 2. More details about the design and test of the wind tunnel are shown in reference ${ }^{[26]}$.

\subsection{Spray control system}

The spray control system was designed to control and record the pressure and flow rate in the tube. It had a water storage tank, a diaphragm pump, a buffer tank, a reducing valve, a pressure sensor, a flow meter and a spray nozzle. The pressure transducer was mounted at the same height with the nozzle. The flow rate and spray pressure was controlled and recorded accurately by adjusting the reducing valve. The pressure sensor was mounted at the same height with the nozzle.

A schematic of the spray control system is given in Fig. 3.

\subsection{Data acquisition}

A Malvern Spraytec laser diffraction instrument was used to measure the spectra of droplet size. It was an automated, real-time and high-speed measuring system. Its acquisition rate was about $10 \mathrm{kHz}$, with a size measuring range of $0.1-900 \mu \mathrm{m}$.

The nozzle was fixed on an optimal platform and could be twisted to adjust the atomization zone. The nominal spray angle of the nozzle is 120 degree, but influenced by the high speed air flow, the real angle of the plume is less

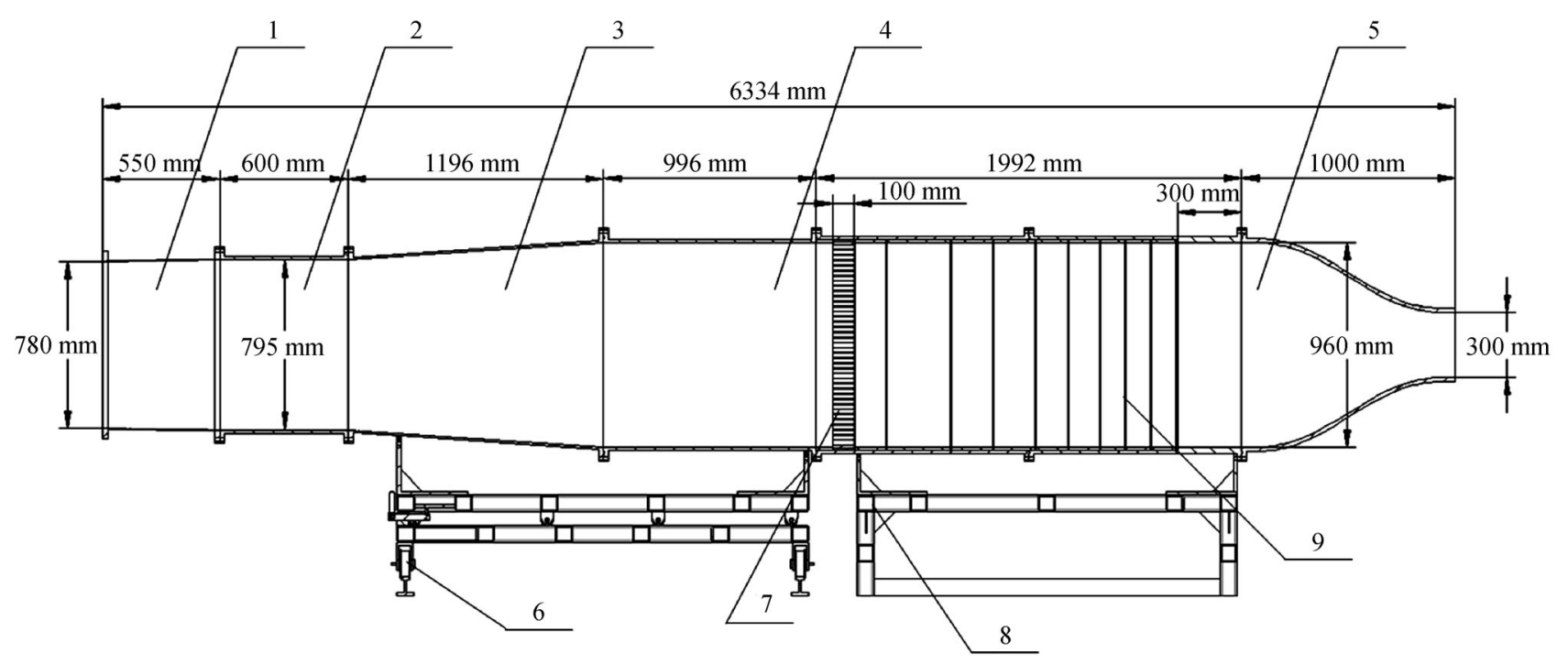

Fig. 2 Structure diagram of the IEA-I high-speed wind tunnel ${ }^{[26]}$. 1, Adapter; 2, shock absorber; 3, diffuser; 4, settling chamber; 5 , contraction section; 6 , rail; 7 , honey comb; 8 , fixed support; 9 , screen meshes.

Table 2 Parameters of the IEA-I high-speed wind tunnel

\begin{tabular}{lc}
\hline Parameter & Technical index \\
\hline Form of structure & Open-circuit blow-down wind tunnel \\
Test section diameter & $300 \mathrm{~mm}$ \\
Wind speed & $24-350 \mathrm{~km} \cdot \mathrm{h}^{-1}$ \\
Turbulent intensity & $<1.0 \%$ \\
Coefficient of variation & $<0.5 \%$ \\
Dynamic pressure stability coefficient & $<2.0 \%$ \\
Inclined angle & $<0.5 \mathrm{deg}$ \\
Normalized axial static pressure gradient & $0.02(0-0.46 \mathrm{~m}$ outside the exit)
\end{tabular}




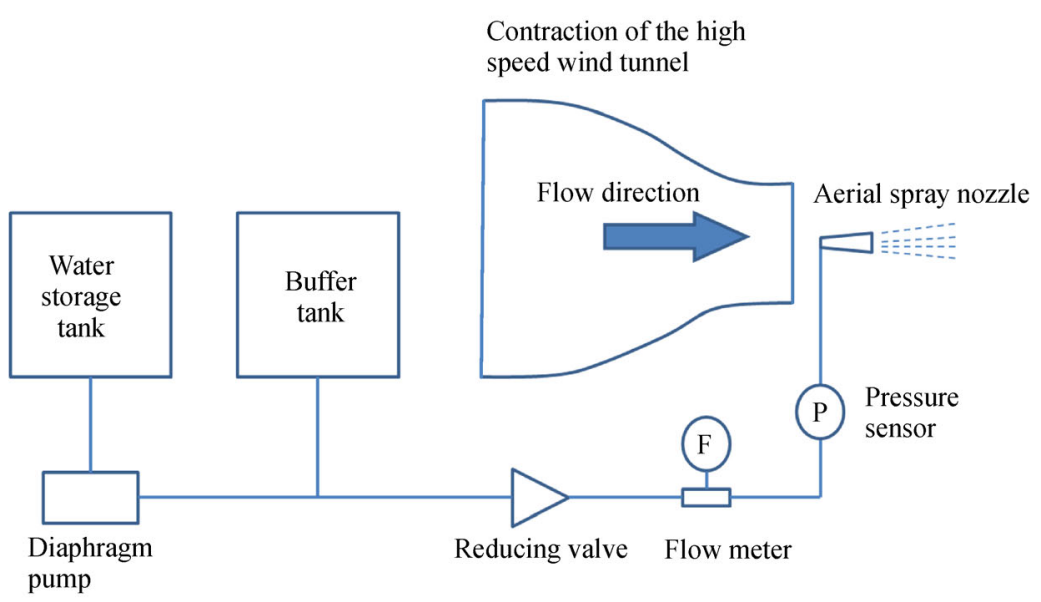

Fig. 3 Schematic diagram of the spray control system

than 45 degree. The laser diffraction instrument was installed on an electric lifting platform, which could be traversed vertically such that the entire spray plume could be sampled within a given replicated measurement. The speed of the platform was set to $5 \mathrm{~mm} \cdot \mathrm{s}^{-1}$, and the scanning distance was about $250 \mathrm{~mm}$. This scanning distance is in the range of the exit diameter of the test section, it is also large enough to sample the entire spray plume of the nozzle. The leeward view of the measuring schematic is shown in Fig. 4.

The Malvern analyzer operates on the basis of light scattering and there were concerns that the internal structures of droplets with air inclusions may influence the values obtained when measuring droplet size distributions from air induction nozzles with this instrument. However, Powell et al. ${ }^{[18]}$ found that the Malvern analyzer can be used to measure droplet size distribution in sprays from air induction nozzles with reasonable confidence over a range of relevant conditions.

\section{Results and discussion}

\subsection{Effect of the measuring distance}

First, the study focused on the effect of the measuring point on the atomization of the droplets. The droplets size data for the IDK120-03 nozzle at spray pressure of $0.4 \mathrm{MPa}$ measured using laser diffraction at each measurement distance and air speed are shown in Table 3.

Figure 5 shows that spectra of the droplet size were influenced both by distance of the measuring point from the nozzle orifice and wind speed. When wind speed was less than $150 \mathrm{~km} \cdot \mathrm{h}^{-1}, D \mathrm{v}_{0.5}, \mathrm{RS}, \%<100 \mu \mathrm{m}$ and $\%<$ $200 \mu \mathrm{m}$ of the droplets were almost the same at $0.15,0.25$ and $0.35 \mathrm{~m}$ from the nozzle orifice. However, when wind speed was increased, the measuring distance had an impact.

As shown in Fig. 5a, when the measuring point was $0.15 \mathrm{~m}$ from the nozzle orifice, $D \mathrm{v}_{0.5}$ of droplets was about

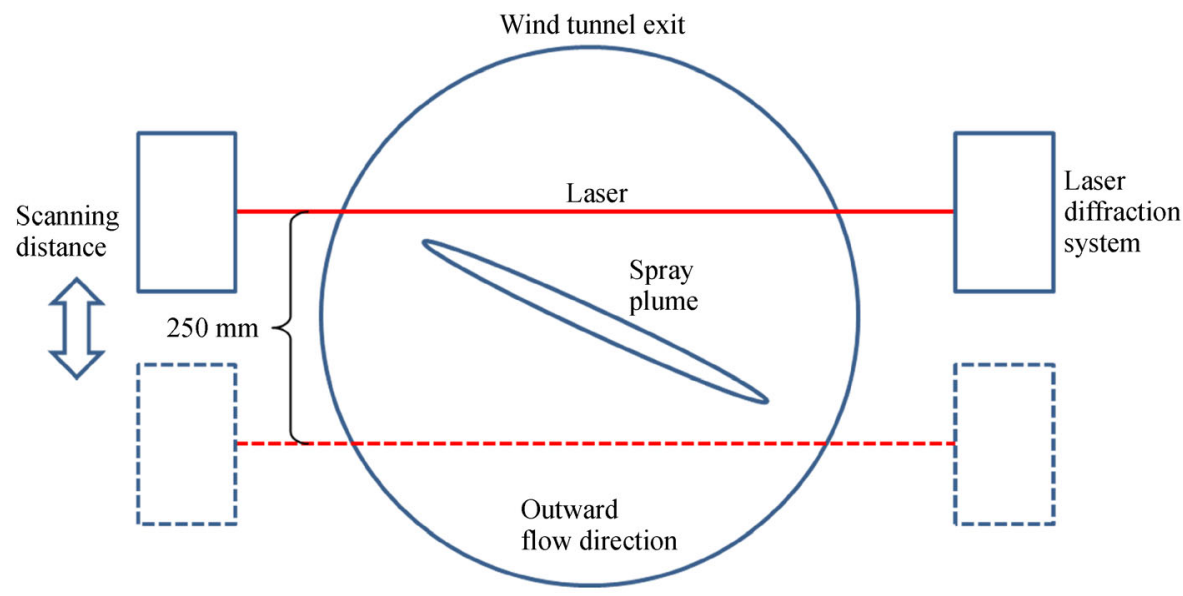

Fig. 4 Schematic diagram of the spray measurement from the leeward view 
Table 3 Droplet size data measured using the Malvern laser diffraction system for IDK120-03 nozzle operating at $0.4 \mathrm{MPa}$

\begin{tabular}{|c|c|c|c|c|c|c|c|}
\hline Distance from the orifice $/ \mathrm{m}$ & Wind speed $/\left(\mathrm{km} \cdot \mathrm{h}^{-1}\right)$ & $D \mathrm{v}_{0.5} / \mu \mathrm{m}$ & $D \mathrm{v}_{0.1} / \mu \mathrm{m}$ & $D \mathrm{v}_{0.9} / \mu \mathrm{m}$ & $\mathrm{RS}$ & $\%<100 \mu \mathrm{m}$ & $\%<200 \mu \mathrm{m}$ \\
\hline \multirow[t]{7}{*}{0.15} & 121.7 & 426.8 & 210.5 & 740.5 & 1.242 & 1.56 & 8.62 \\
\hline & 153.4 & 403.6 & 195.1 & 722.8 & 1.308 & 1.70 & 10.74 \\
\hline & 185.5 & 367.6 & 172.5 & 692.0 & 1.414 & 2.28 & 14.89 \\
\hline & 218.4 & 312.6 & 141.7 & 636.6 & 1.583 & 3.75 & 23.23 \\
\hline & 253.5 & 257.2 & 115.9 & 555.5 & 1.709 & 6.68 & 34.13 \\
\hline & 277.5 & 212.7 & 95.0 & 477.6 & 1.797 & 11.42 & 46.05 \\
\hline & 305.5 & 175.7 & 78.1 & 402 & 1.843 & 18.32 & 58.17 \\
\hline \multirow[t]{7}{*}{0.25} & 121.7 & 428.6 & 215.3 & 740.7 & 1.226 & 1.44 & 7.98 \\
\hline & 153.4 & 401.3 & 196.1 & 719.2 & 1.303 & 1.72 & 10.60 \\
\hline & 185.5 & 354.2 & 167.0 & 676.6 & 1.439 & 2.39 & 16.28 \\
\hline & 218.4 & 292.2 & 136.3 & 595.6 & 1.572 & 4.16 & 25.98 \\
\hline & 253.5 & 234.1 & 110.4 & 477.5 & 1.568 & 7.58 & 39.14 \\
\hline & 277.5 & 188.4 & 87.4 & 375.4 & 1.528 & 14.13 & 54.21 \\
\hline & 305.5 & 157.6 & 73.3 & 307.7 & 1.487 & 21.39 & 66.88 \\
\hline \multirow[t]{7}{*}{0.35} & 121.7 & 424.3 & 213.3 & 737.0 & 1.234 & 1.49 & 8.19 \\
\hline & 153.4 & 397.5 & 195.0 & 714.6 & 1.307 & 1.79 & 10.76 \\
\hline & 185.5 & 348.6 & 168.5 & 663.5 & 1.420 & 2.47 & 16.09 \\
\hline & 218.4 & 282.4 & 136.1 & 558.2 & 1.495 & 4.35 & 26.69 \\
\hline & 253.5 & 225.8 & 110.1 & 428.3 & 1.410 & 7.69 & 40.96 \\
\hline & 277.5 & 184.7 & 87.9 & 343.0 & 1.381 & 13.85 & 56.05 \\
\hline & 305.5 & 154.9 & 72.6 & 290.3 & 1.405 & 21.69 & 68.87 \\
\hline
\end{tabular}

$10 \%$ larger than when measured 0.25 and $0.35 \mathrm{~m}$ from the nozzle orifice over a wind speed range of $180-300 \mathrm{~km} \cdot \mathrm{h}^{-1}$, which indicates that $0.15 \mathrm{~m}$ is not long enough for the droplets to be atomized sufficiently. It is easy to imagine that when the wind speed increases, the liquid will move a greater distance before it is fully atomized.

Figure $5 \mathrm{~b}$ shows that RS of droplets increased with wind speed at the measuring point of $0.15 \mathrm{~m}$. It was also evident that at the measuring points of 0.25 and $0.35 \mathrm{~m}$, RS stopped increasing when wind speed exceeded $220 \mathrm{~km} \cdot \mathrm{h}^{-1}$ However, RS of droplets is not a direct physical parameter and it is difficult to analyze it in this figure.

Figure $5 \mathrm{c}$ and Figure $5 \mathrm{~d}$ could be utilized to explain this phenomenon, for RS is defined by the formula $\left(D \mathrm{v}_{0.9}-D \mathrm{v}_{0.1}\right) / D \mathrm{v}_{0.5}$. When the measuring distance was increased, small droplets did not change much, but the size of large droplets decreased greatly. A possible reason is that the instrument measures the droplet size by calculating the numbers of droplets across the laser spot in a unit time. When the wind speed increased, big droplets are easily calculated repetitively comparing with the smaller ones because of their lower speed and big inertia, which may cause an over-predicted value of droplet size $\mathrm{e}^{[15,27,28]}$. Another possible reason is that large droplets need to take longer time and distance to break up into smaller droplets. In Fig. $5 \mathrm{~d}$ it could be seen that there is a great difference of
$D \mathrm{v}_{0.9}$ between the measuring distance of $0.15 \mathrm{~m}$ and $0.25 \mathrm{~m}$. There was also a smaller difference of $D \mathrm{v}_{0.9}$ between the measuring distance of $0.25 \mathrm{~m}$ and $0.35 \mathrm{~m}$, which indicates that at the measuring distance of $0.35 \mathrm{~m}$ the large droplets still may not be fully atomized.

Figure $5 \mathrm{e}$ and Figure $5 \mathrm{f}$ show little difference between the measuring points at 0.25 and $0.35 \mathrm{~m}$ for $\%<100 \mu \mathrm{m}$ and $\%<200 \mu \mathrm{m}$, which were larger than the results at the measuring point at $0.15 \mathrm{~m}$. This also indicates that $0.15 \mathrm{~m}$ was insufficient to obtain fully atomized droplets.

As shown in Fig. 5, it is obvious that the further the measuring point was away from the nozzle orifice, the more the droplets were atomized. However, flow field quality outside the exit of the wind tunnel should not be ignored $^{[26]}$. When the measuring point was too far away from the exit of the wind tunnel, the flow field (wind speed/ fluctuations) changed. The spray plume may also exceed the measuring range of the laser diffraction instrument and the uniform flow field of the wind tunnel test section. As a tradeoff of the above situations, a measuring point of $0.35 \mathrm{~m}$ was chosen for the following analysis.

\subsection{Effect of the nozzle type, spray pressure and wind speed}

The droplet size data for different orifice sizes, wind speeds and spray pressures were measured systematically and the 
(a)

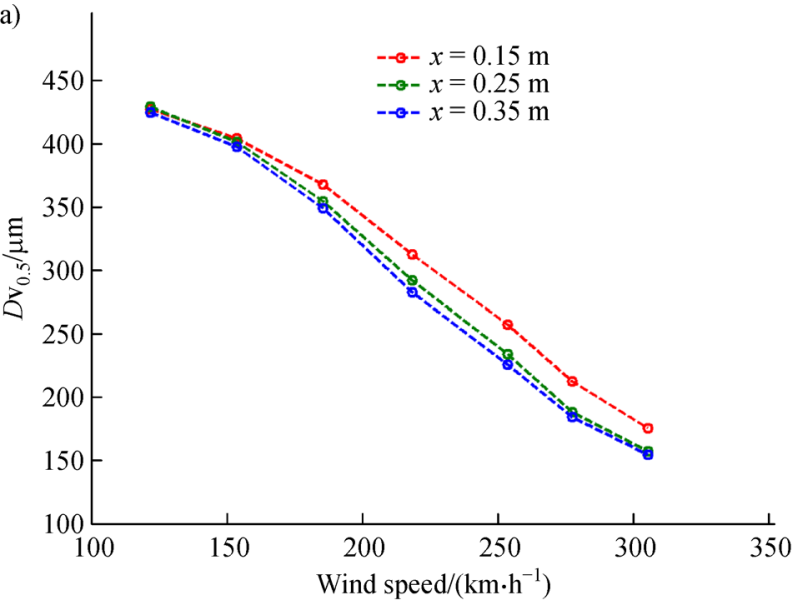

(c)

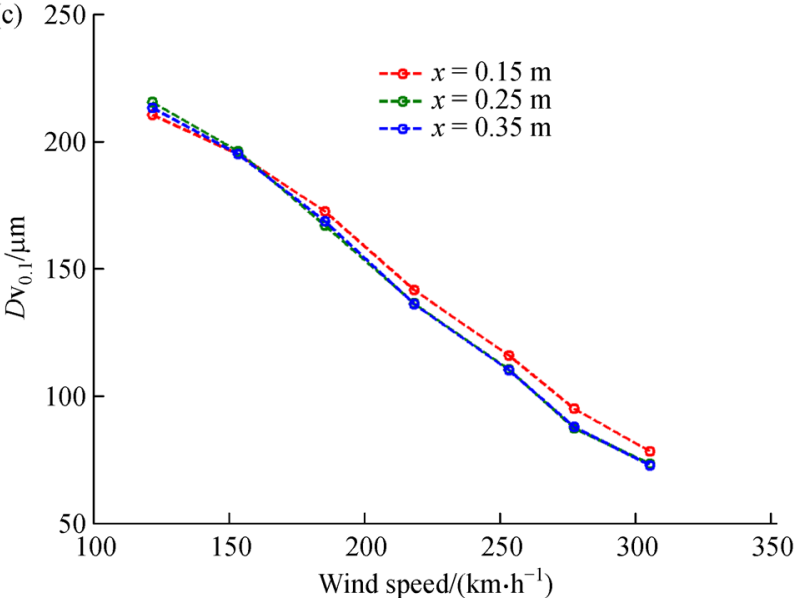

(e)

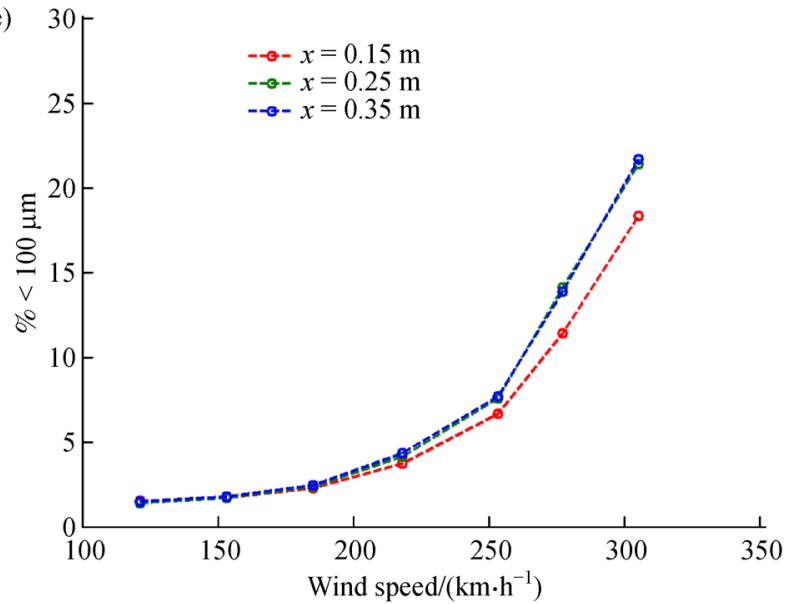

(b)

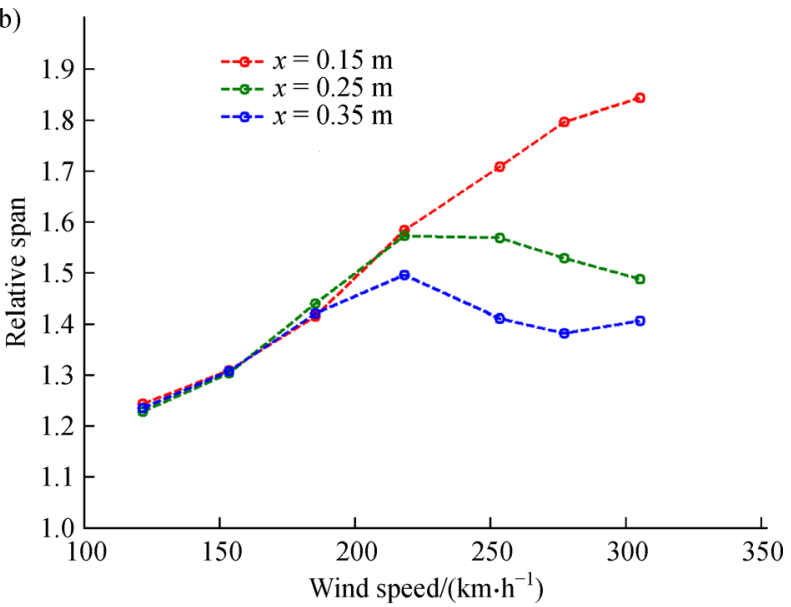

(d)

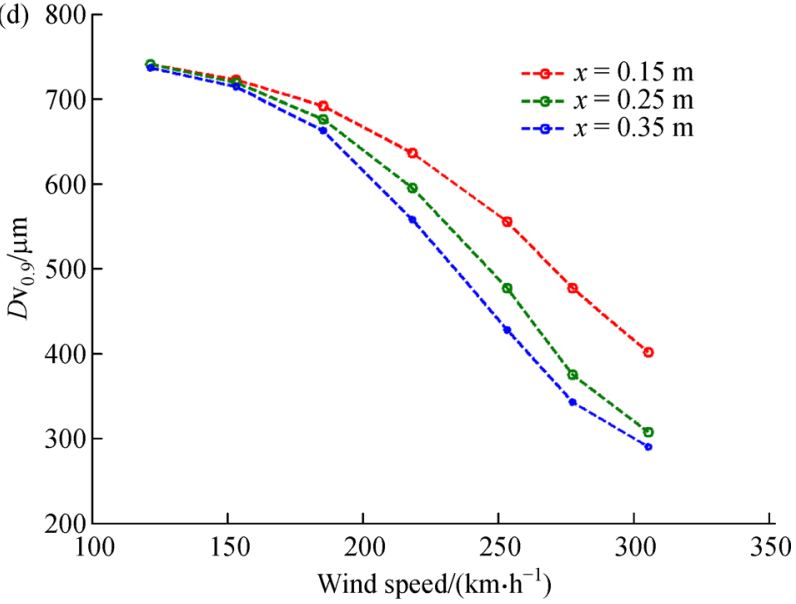

(f)

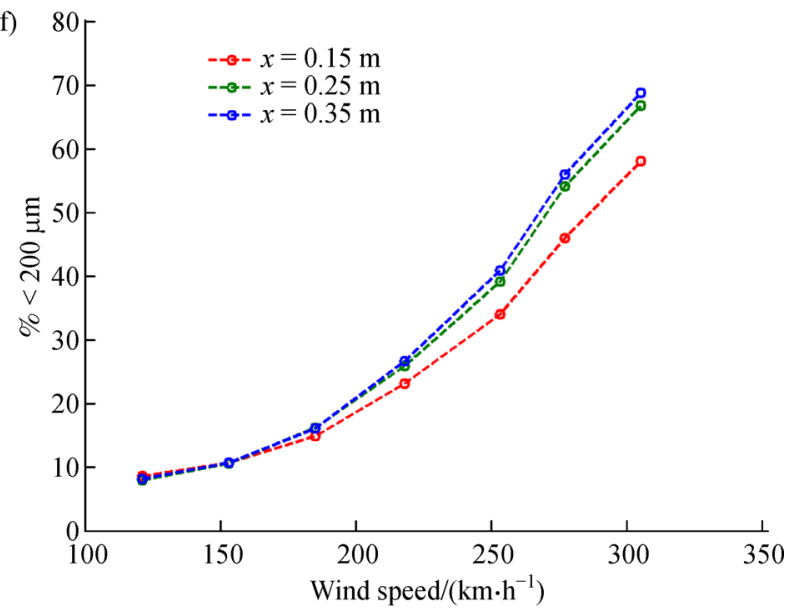

Fig. $5 D \mathrm{v}_{0.5}$ (a), RS (b), $D \mathrm{v}_{0.1}$ (c), $D \mathrm{v}_{0.9}$ (d), $\%<100 \mu \mathrm{m}$ (e) and $\%<200 \mu \mathrm{m}$ (f) measured at $0.15,0.25$ and $0.35 \mathrm{~m}$ from the nozzle orifice

detailed results are shown in Table 4.

The response surface method was used to analyze the above results. Similar to $\operatorname{Kirk}^{[8]}$ and Fritz \& Hoffmann ${ }^{[16]}$, second-order response relationships were fitted using Eq. (1) for data collected for each nozzle and model type evaluated:

$$
\begin{aligned}
Y= & A X_{1}+B X_{2}+C X_{3}+D X_{1}^{2}+E X_{2}^{2}+F X_{2}^{2} \\
& +G X_{1} X_{2}+H X_{2} X_{3}+I X_{1} X_{3}
\end{aligned}
$$

where $Y$ is the predicted atomization parameter based on specification of inputs $X_{1}$ to $X_{3}\left(D \mathrm{v}_{0.5}, D \mathrm{v}_{0.1}, D \mathrm{v}_{0.9}, \mathrm{RS}\right.$, $\%<100 \mu \mathrm{m}$ and $\%<200 \mu \mathrm{m}), \quad X_{1}$ is the airspeed $\left(\mathrm{km} \cdot \mathrm{h}^{-1}\right), X_{2}$ is the spray pressure $(\mathrm{MPa}), X_{3}$ is the orifice size (unitless, specific orifice number for each nozzle based on the flow rate at fixed spray pressure ${ }^{[29]}$ ), and $A$ to $I$ are the coefficients for respective terms of the equation.

Coefficients of the response surface equations for IDK nozzle are shown in Table 5. A quadratic process and a 
Table 4 Droplet sizes data measured using Malvern laser diffraction system at $0.35 \mathrm{~m}$

\begin{tabular}{|c|c|c|c|c|c|c|c|c|}
\hline Spray pressure/MPa & Nozzle type & Wind speed $/\left(\mathrm{km} \cdot \mathrm{h}^{-1}\right)$ & $D \mathrm{v}_{0.5} / \mu \mathrm{m}$ & $D \mathrm{v}_{0.1} / \mu \mathrm{m}$ & $D \mathrm{v}_{0.9} / \mu \mathrm{m}$ & RS & $\%<100 \mu \mathrm{m}$ & $\%<200 \mu \mathrm{m}$ \\
\hline \multirow[t]{28}{*}{0.3} & \multirow[t]{7}{*}{ IDK-120-01 } & 121.7 & 414.2 & 205.7 & 728.7 & 1.263 & 1.53 & 9.193 \\
\hline & & 153.4 & 373.6 & 185.6 & 687.0 & 1.343 & 1.97 & 12.51 \\
\hline & & 185.5 & 315.8 & 159.2 & 603.3 & 1.406 & 2.68 & 19.36 \\
\hline & & 218.4 & 255.2 & 131.6 & 471.9 & 1.334 & 4.32 & 31.43 \\
\hline & & 253.5 & 209.0 & 107.2 & 375.0 & 1.282 & 8.12 & 46.44 \\
\hline & & 277.5 & 175.3 & 88.5 & 317.5 & 1.307 & 14.16 & 60.61 \\
\hline & & 305.5 & 151.4 & 76.4 & 285.5 & 1.381 & 21.17 & 71.09 \\
\hline & \multirow[t]{7}{*}{ IDK-120-02 } & 121.7 & 408.2 & 204.3 & 722.4 & 1.270 & 1.48 & 9.37 \\
\hline & & 153.4 & 375.6 & 185.3 & 690.5 & 1.345 & 1.92 & 12.52 \\
\hline & & 185.5 & 322.9 & 160.4 & 618.7 & 1.419 & 2.69 & 18.69 \\
\hline & & 218.4 & 265.2 & 135.8 & 498.7 & 1.369 & 3.92 & 29.03 \\
\hline & & 253.5 & 214.2 & 106.8 & 393.3 & 1.337 & 8.27 & 44.66 \\
\hline & & 277.5 & 178.7 & 87.9 & 330.5 & 1.357 & 14.16 & 58.78 \\
\hline & & 305.5 & 154.1 & 74.3 & 306.0 & 1.504 & 21.43 & 68.90 \\
\hline & \multirow[t]{7}{*}{ IDK-120-03 } & 121.7 & 442.9 & 233.7 & 746.4 & 1.158 & 0.99 & 5.73 \\
\hline & & 153.4 & 408.1 & 203.3 & 723.6 & 1.275 & 1.71 & 9.52 \\
\hline & & 185.5 & 350.7 & 169.8 & 666.7 & 1.417 & 2.42 & 15.83 \\
\hline & & 218.4 & 280.4 & 136.9 & 552.8 & 1.483 & 4.07 & 26.89 \\
\hline & & 253.5 & 221.3 & 107.9 & 419.6 & 1.408 & 8.07 & 42.46 \\
\hline & & 277.5 & 181.9 & 87.4 & 338.0 & 1.378 & 14.25 & 57.18 \\
\hline & & 305.5 & 152.8 & 71.5 & 286.3 & 1.406 & 22.44 & 69.73 \\
\hline & \multirow[t]{7}{*}{ IDK-120-04 } & 121.7 & 471.6 & 257.9 & 767.5 & 1.081 & 0.87 & 3.74 \\
\hline & & 153.4 & 434.1 & 221.7 & 743.8 & 1.203 & 1.49 & 7.23 \\
\hline & & 185.5 & 367.9 & 181.4 & 682.2 & 1.362 & 2.17 & 13.29 \\
\hline & & 218.4 & 293.8 & 144.1 & 574.2 & 1.464 & 3.67 & 23.98 \\
\hline & & 253.5 & 234.4 & 114.3 & 451.1 & 1.437 & 6.95 & 38.30 \\
\hline & & 277.5 & 190.6 & 92.1 & 359.5 & 1.404 & 12.43 & 53.68 \\
\hline & & 305.5 & 160.5 & 76.7 & 308.2 & 1.443 & 19.60 & 66.30 \\
\hline \multirow[t]{28}{*}{0.4} & \multirow[t]{7}{*}{ IDK-120-01 } & 121.7 & 383.1 & 186.6 & 703.0 & 1.348 & 1.47 & 12.30 \\
\hline & & 153.4 & 350.3 & 171.9 & 663.9 & 1.405 & 1.84 & 15.59 \\
\hline & & 185.5 & 303.5 & 153.6 & 583.5 & 1.417 & 2.50 & 21.49 \\
\hline & & 218.4 & 251.7 & 129.6 & 472.6 & 1.363 & 4.24 & 32.62 \\
\hline & & 253.5 & 208.2 & 105.0 & 384.0 & 1.341 & 8.64 & 46.88 \\
\hline & & 277.5 & 177.3 & 90.3 & 325.0 & 1.324 & 13.59 & 59.52 \\
\hline & & 305.5 & 151.2 & 75.7 & 283.1 & 1.372 & 21.59 & 71.04 \\
\hline & \multirow[t]{7}{*}{ IDK-120-02 } & 121.7 & 389.9 & 196.6 & 704.3 & 1.306 & 1.52 & 10.81 \\
\hline & & 153.4 & 359.2 & 177.0 & 671.6 & 1.377 & 2.01 & 14.28 \\
\hline & & 185.5 & 317.2 & 157.0 & 611.4 & 1.433 & 2.74 & 19.74 \\
\hline & & 218.4 & 263.4 & 132.0 & 500.7 & 1.401 & 4.46 & 29.97 \\
\hline & & 253.5 & 215.7 & 108.0 & 395.4 & 1.332 & 8.01 & 44.11 \\
\hline & & 277.5 & 180.4 & 89.2 & 330.1 & 1.336 & 13.69 & 58.14 \\
\hline & & 305.5 & 153.8 & 74.8 & 287.7 & 1.385 & 21.17 & 69.81 \\
\hline & \multirow[t]{7}{*}{ IDK-120-03 } & 121.7 & 424.3 & 213.3 & 737.0 & 1.234 & 1.49 & 8.19 \\
\hline & & 153.4 & 397.5 & 195.0 & 714.6 & 1.307 & 1.79 & 10.76 \\
\hline & & 185.5 & 348.6 & 168.5 & 663.5 & 1.420 & 2.47 & 16.09 \\
\hline & & 218.4 & 282.4 & 136.1 & 558.2 & 1.495 & 4.35 & 26.69 \\
\hline & & 253.5 & 225.8 & 110.1 & 428.3 & 1.410 & 7.69 & 40.96 \\
\hline & & 277.5 & 184.7 & 87.9 & 343.0 & 1.381 & 13.85 & 56.05 \\
\hline & & 305.5 & 154.9 & 72.6 & 290.3 & 1.405 & 21.69 & 68.87 \\
\hline & \multirow[t]{7}{*}{ IDK-120-04 } & 121.7 & 445.3 & 235.3 & 749.2 & 1.155 & 1.09 & 5.66 \\
\hline & & 153.4 & 414.5 & 209.0 & 727.0 & 1.249 & 1.51 & 8.67 \\
\hline & & 185.5 & 360.8 & 178.7 & 672.5 & 1.369 & 2.15 & 13.93 \\
\hline & & 218.4 & 290.2 & 143.6 & 560.3 & 1.436 & 3.70 & 24.38 \\
\hline & & 253.5 & 230.9 & 114.1 & 428.1 & 1.360 & 6.97 & 39.08 \\
\hline & & 277.5 & 190.4 & 95.2 & 349.4 & 1.343 & 11.96 & 53.86 \\
\hline & & 305.5 & 160.1 & 77.0 & 295.9 & 1.368 & 19.46 & 66.95 \\
\hline
\end{tabular}


(Continued)

\begin{tabular}{|c|c|c|c|c|c|c|c|c|}
\hline Spray pressure/MPa & Nozzle type & Wind speed $/\left(\mathrm{km} \cdot \mathrm{h}^{-1}\right)$ & $D \mathrm{v}_{0.5} / \mu \mathrm{m}$ & $D \mathrm{v}_{0.1} / \mu \mathrm{m}$ & $D \mathrm{v}_{0.9} / \mu \mathrm{m}$ & RS & $\%<100 \mu \mathrm{m}$ & $\%<200 \mu \mathrm{m}$ \\
\hline \multirow[t]{28}{*}{0.5} & \multirow[t]{7}{*}{ IDK-120-01 } & 121.7 & 361.8 & 173.6 & 683.0 & 1.408 & 1.85 & 14.94 \\
\hline & & 153.4 & 330.0 & 161.2 & 634.1 & 1.433 & 2.50 & 18.25 \\
\hline & & 185.5 & 289.2 & 145.2 & 554.0 & 1.414 & 3.29 & 24.25 \\
\hline & & 218.4 & 248.9 & 128.6 & 465.9 & 1.356 & 4.23 & 33.39 \\
\hline & & 253.5 & 207.8 & 108.0 & 375.2 & 1.286 & 7.76 & 46.93 \\
\hline & & 277.5 & 176.6 & 90.2 & 320.8 & 1.307 & 13.66 & 59.96 \\
\hline & & 305.5 & 151.6 & 76.6 & 282.2 & 1.356 & 21.21 & 71.00 \\
\hline & \multirow[t]{7}{*}{ IDK-120-02 } & 121.7 & 367.2 & 182.4 & 680.9 & 1.358 & 1.70 & 13.19 \\
\hline & & 153.4 & 348.4 & 170.3 & 659.9 & 1.406 & 2.20 & 15.80 \\
\hline & & 185.5 & 314.8 & 154.1 & 612.2 & 1.456 & 2.88 & 20.49 \\
\hline & & 218.4 & 269.6 & 132.5 & 530.4 & 1.476 & 4.35 & 29.12 \\
\hline & & 253.5 & 220.3 & 109.2 & 413.9 & 1.383 & 7.76 & 42.64 \\
\hline & & 277.5 & 184.6 & 90.6 & 347.3 & 1.390 & 13.10 & 56.15 \\
\hline & & 305.5 & 157.6 & 76.3 & 308.2 & 1.472 & 20.27 & 67.43 \\
\hline & \multirow[t]{7}{*}{ IDK-120-03 } & 121.7 & 423.2 & 210.3 & 736.3 & 1.243 & 1.83 & 8.64 \\
\hline & & 153.4 & 403.5 & 196.8 & 720.3 & 1.298 & 2.03 & 10.47 \\
\hline & & 185.5 & 359.5 & 169.2 & 679.1 & 1.418 & 2.88 & 15.50 \\
\hline & & 218.4 & 295.2 & 136.9 & 591.6 & 1.540 & 4.55 & 25.09 \\
\hline & & 253.5 & 233.1 & 108.9 & 460.4 & 1.509 & 8.02 & 39.22 \\
\hline & & 277.5 & 185.8 & 85.9 & 353.4 & 1.440 & 14.48 & 55.41 \\
\hline & & 305.5 & 154.2 & 71.2 & 293.8 & 1.440 & 22.44 & 68.73 \\
\hline & \multirow[t]{7}{*}{ IDK-120-04 } & 121.7 & 429.2 & 222.3 & 736.3 & 1.198 & 0.99 & 6.96 \\
\hline & & 153.4 & 409.2 & 206.8 & 720.6 & 1.408 & 1.85 & 14.94 \\
\hline & & 185.5 & 364.0 & 175.2 & 684.8 & 1.433 & 2.50 & 18.25 \\
\hline & & 218.4 & 300.2 & 144.9 & 597.9 & 1.414 & 3.29 & 24.25 \\
\hline & & 253.5 & 236.1 & 116.2 & 447.4 & 1.356 & 4.23 & 33.39 \\
\hline & & 277.5 & 193.2 & 93.8 & 357.4 & 1.286 & 7.76 & 46.93 \\
\hline & & 305.5 & 162.0 & 77.6 & 300.1 & 1.307 & 13.66 & 59.96 \\
\hline
\end{tabular}

modified process were used to find the dominant factors affecting droplet size spectra.

The quadratic model was applied to the $D \mathrm{v}_{0.5}$ result (Fig. 6), which was inversely proportional to the wind speed. The $D \mathrm{v}_{0.5}$ of the droplets was also found proportional to the orifice size. Meanwhile, increasing spray pressure could slightly reduce $D \mathrm{v}_{0.5}$ under low speed conditions and slightly increase $D \mathrm{v}_{0.5}$ under high speed conditions.

The simplified equation of $D \mathrm{v}_{0.5}$ is:

$$
D \mathrm{v}_{0.5}=566.9-1.49 X_{1}+143.3 X_{3}(\mu \mathrm{m})
$$

As indicated by Guler et al. ${ }^{[23]}$, the generation of the droplets by air induction nozzle originates from the breakdown of the liquid sheet. The breakdown process of the liquid sheet is accelerated by the bubbles generated by the air induction nozzle. The bubbles experience a sudden pressure relaxation and expand rapidly, thereby shattering the liquid into drops. A typical breakdown process of the liquid sheet was mentioned by Dombrowski \& Johns ${ }^{[30]}$.

Based on the linear stability theory of the inviscid liquid sheet break down process, the droplet size is controlled by the equations ${ }^{[31,32]}$ :

$$
\begin{aligned}
& D \mathrm{v}_{0.5}=\operatorname{const}\left(\frac{1}{f}\right)^{1 / 3}\left[\frac{\mathrm{C}^{2} \sigma_{l}^{2}}{\rho_{g} \rho_{l}\left(U_{g}-U_{l}\right)^{4}}\right]^{1 / 6} \\
& f=\ln \frac{\eta_{b}}{\eta_{0}}=W e^{0.37} \operatorname{Re}^{0.07}=\frac{\alpha^{0.44} \rho_{l}^{0.44} U_{l}^{0.81}}{\mu_{l}^{0.07} \sigma_{l}^{0.37}}
\end{aligned}
$$

where $\alpha$ is the thickness of the liquid sheet, $\rho_{g}$ is the air density and $\rho_{l}$ is the liquid density, $\eta_{b}$ is the wave amplitude when the liquid sheet breakdown and $\eta_{0}$ is the initial wave amplitude. $\mathrm{C}$ is a constant proportional to the size of the nozzle orifice, $\sigma_{l}$ is the surface tension of the liquid, $U_{g}$ is the air speed and $U_{l}$ is the liquid sheet speed.

From the Eq. (3) it can easily be derived that the $D \mathrm{v}_{0.5}$ of the droplets is proportional to the nozzle orifice size. Based on the test speed range of this paper, the air speed $U_{g}$ is much larger than the liquid sheet speed $U_{l}$, the increase of the wind speed will reduce the $D v_{0.5}$ of the droplets. Ignoring the linear loss of the tube flow, we obtained $\Delta \rho \propto U_{l}^{2}$. When the spray pressure increases, the breakup parameter $f$ increases, but the velocity difference $U_{g}-U_{l}$ 
Table 5 Coefficients of the response surface equations for IDK nozzle

\begin{tabular}{|c|c|c|c|}
\hline IDK nozzle & Factors & Quadratic & Modified \\
\hline \multirow[t]{11}{*}{$\overline{D \mathrm{v}_{0.5} / \mu \mathrm{m}}$} & Intercept & +667.33268 & +566.90032 \\
\hline & $X_{1}$ & -1.54002 & -1.48646 \\
\hline & $X_{2}$ & -548.47754 & NA \\
\hline & $X_{3}$ & +313.86764 & +143.31905 \\
\hline & $X_{1} X_{2}$ & +1.11966 & NA \\
\hline & $X_{1} X_{3}$ & -1.30482 & NA \\
\hline & $X_{2} X_{3}$ & +201.14286 & NA \\
\hline & $X_{1}^{2}$ & -0.00016 & NA \\
\hline & $X_{2}^{2}$ & +268.92857 & NA \\
\hline & $X_{3}^{2}$ & +62.97619 & NA \\
\hline & $R^{2}$ & 0.9892 & 0.9747 \\
\hline \multirow[t]{11}{*}{$D \mathrm{v}_{0.1} / \mu \mathrm{m}$} & Intercept & +349.79038 & +287.18927 \\
\hline & $X_{1}$ & -0.90314 & -0.76261 \\
\hline & $X_{2}$ & -287.04831 & NA \\
\hline & $X_{3}$ & +173.97654 & +69.10476 \\
\hline & $X_{1} X_{2}$ & +0.74849 & NA \\
\hline & $X_{1} X_{3}$ & -0.98485 & NA \\
\hline & $X_{2} X_{3}$ & +47.35714 & NA \\
\hline & $X_{1}^{2}$ & +0.00020 & NA \\
\hline & $X_{2}^{2}$ & +98.39286 & NA \\
\hline & $X_{3}^{2}$ & +178.80952 & NA \\
\hline & $R^{2}$ & 0.9926 & 0.9621 \\
\hline \multirow[t]{11}{*}{$D \mathrm{v}_{0.9} / \mu \mathrm{m}$} & Intercept & +8.09386 & +829.71053 \\
\hline & $X_{1}$ & -0.25499 & -0.62237 \\
\hline & $X_{2}$ & +73.32265 & NA \\
\hline & $X_{3}$ & -16.54223 & +220.55714 \\
\hline & $X_{1} X_{2}$ & -0.15258 & NA \\
\hline & $X_{1} X_{3}$ & +0.040531 & NA \\
\hline & $X_{2} X_{3}$ & -35.50786 & NA \\
\hline & $X_{1}^{2}$ & +0.00150 & -0.00455 \\
\hline & $X_{2}^{2}$ & -34.67321 & NA \\
\hline & $X_{3}^{2}$ & -4.02024 & NA \\
\hline & $R^{2}$ & 0.9955 & 0.9738 \\
\hline \multirow[t]{11}{*}{$\%<100 \mu \mathrm{m}$} & Intercept & +19.89198 & +23.28981 \\
\hline & $X_{1}$ & -0.26713 & -0.28134 \\
\hline & $X_{2}$ & +3.77809 & NA \\
\hline & $X_{3}$ & +14.73769 & NA \\
\hline & $X_{1} X_{2}$ & -0.025250 & NA \\
\hline & $X_{1} X_{3}$ & -0.016430 & NA \\
\hline & $X_{2} X_{3}$ & -3.17857 & NA \\
\hline & $X_{1}^{2}$ & +0.00089 & +0.00089 \\
\hline & $X_{2}^{2}$ & +2.87857 & NA \\
\hline & $X_{3}^{2}$ & -26.12976 & NA \\
\hline & $R^{2}$ & 0.9828 & 0.9780 \\
\hline
\end{tabular}

\begin{tabular}{cccc}
\hline IDK nozzle & Factors & Quadratic & (Continued $)$ \\
\hline$\%<200 \mu \mathrm{m}$ & Intercept & +8.09386 & +29.6513 \\
& $X_{1}$ & -0.25499 & -0.30589 \\
$X_{2}$ & +73.32265 & NA \\
$X_{3}$ & -16.54223 & -23.98043 \\
$X_{1} X_{2}$ & -0.15258 & NA \\
$X_{1} X_{3}$ & +0.040531 & NA \\
$X_{2} X_{3}$ & -35.50786 & NA \\
$X_{1}^{2}$ & +0.00150 & +0.00150 \\
$X_{2}^{2}$ & -34.67321 & NA \\
$X_{3}^{2}$ & -4.02024 & NA \\
$R^{2}$ & 0.9955 & 0.9936 \\
\hline
\end{tabular}

decreases. It is hard to say how the spray pressure affects the $D \mathrm{v}_{0.5}$ of the droplets. When the wind speed increases, the spread angle of the flat fan nozzle decreases accordingly. In this condition, increasing the spray pressure will raise the flow rate and enhance the collision and congregation process, which may cause an increase of the $D \mathrm{v}_{0.5}$ of the droplets. In contrast, when the wind speed decreases, the spread angle of the flat fan nozzle increases accordingly. In this condition, increasing the spray pressure will raise the breakup parameter $f$, which may cause a decrease of the $D \mathrm{v}_{0.5}$ of the droplets. This might be a possible explanation of the phenomenon in Fig. 6b.

In this study, model equations were developed for $D \mathrm{v}_{0.1}$ and $D \mathrm{v}_{0.9}$ along with $D \mathrm{v}_{0.5}$, so RS values were computed with the formula $\left(D \mathrm{v}_{0.9}-D \mathrm{v}_{0.1}\right) / D \mathrm{v}_{0.5}$.

The simplified equation is:

$$
D \mathrm{v}_{0.1}=287.2-0.76 X_{1}+69.1 X_{3}(\mu \mathrm{m})
$$

In Fig. 7 , it could be seen that the $D \mathrm{v}_{0.1}$ has the same trends like $D \mathrm{v}_{0.5}$ of the droplets. A slight difference is that increasing the spray pressure will reduce $D \mathrm{v}_{0.1}$ to a certain extent under low speed conditions and slightly increase it under high speed conditions. The $D \mathrm{v}_{0.1}$ of the droplets is found to be more sensitive to the spray pressure at low speed conditions than $D \mathrm{v}_{0.5}$.

$D \mathrm{v}_{0.9}$ was not the same as $D \mathrm{v}_{0.1}$ and $D \mathrm{v}_{0.5}$. It was proportional to the orifice size and influenced by the quadratic of the wind speed. Meanwhile, it was not markedly influenced by the spray pressure, as shown in Fig. 8.

The simplified equation is:

$$
\begin{aligned}
D \mathrm{v}_{0.9}= & 829.7-0.62 X_{1}+220.6 X_{3} \\
& -4.55 \times 10^{-3} \mathrm{X}_{1}^{2}(\mu \mathrm{m})
\end{aligned}
$$

$D \mathrm{v}_{0.9}$ was more likely to be influenced by the quadratic of the wind speed than $D \mathrm{v}_{0.1}$ and $D \mathrm{v}_{0.5}$, which can be interpreted as follows. 

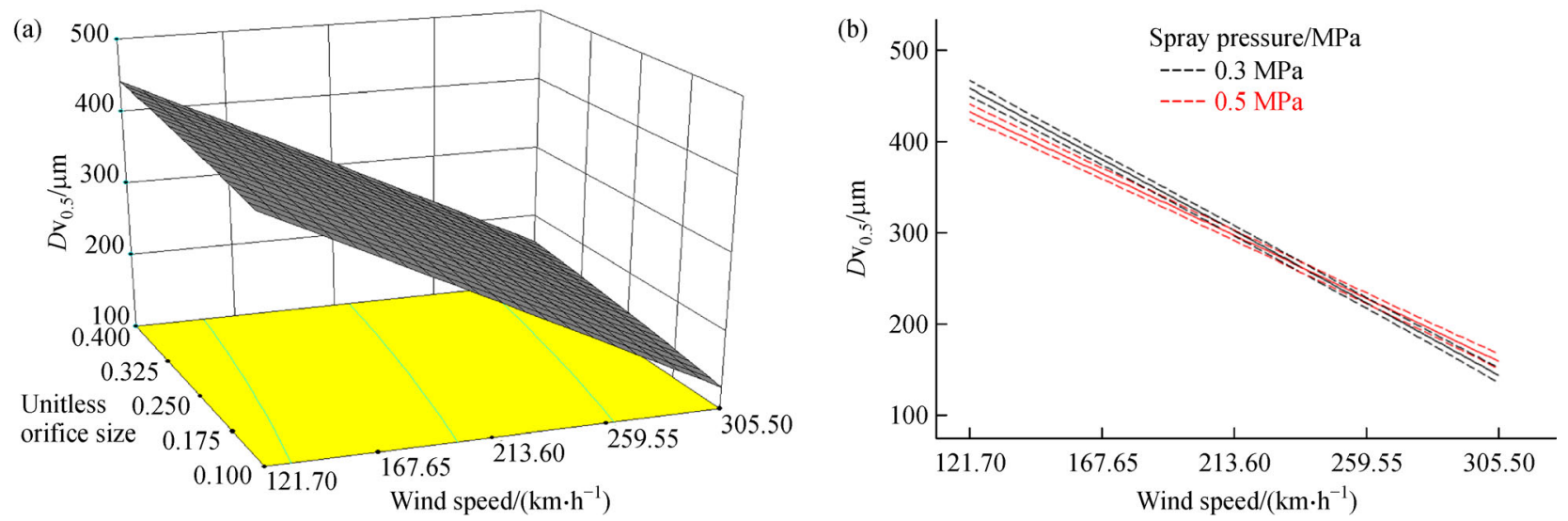

Fig. $63 \mathrm{D}$ response surface of $D \mathrm{v}_{0.5}$ related to the wind speed and orifice size (a) and the effect of the spray pressure and wind speed on $D \mathrm{v}_{0.5}$ (b)
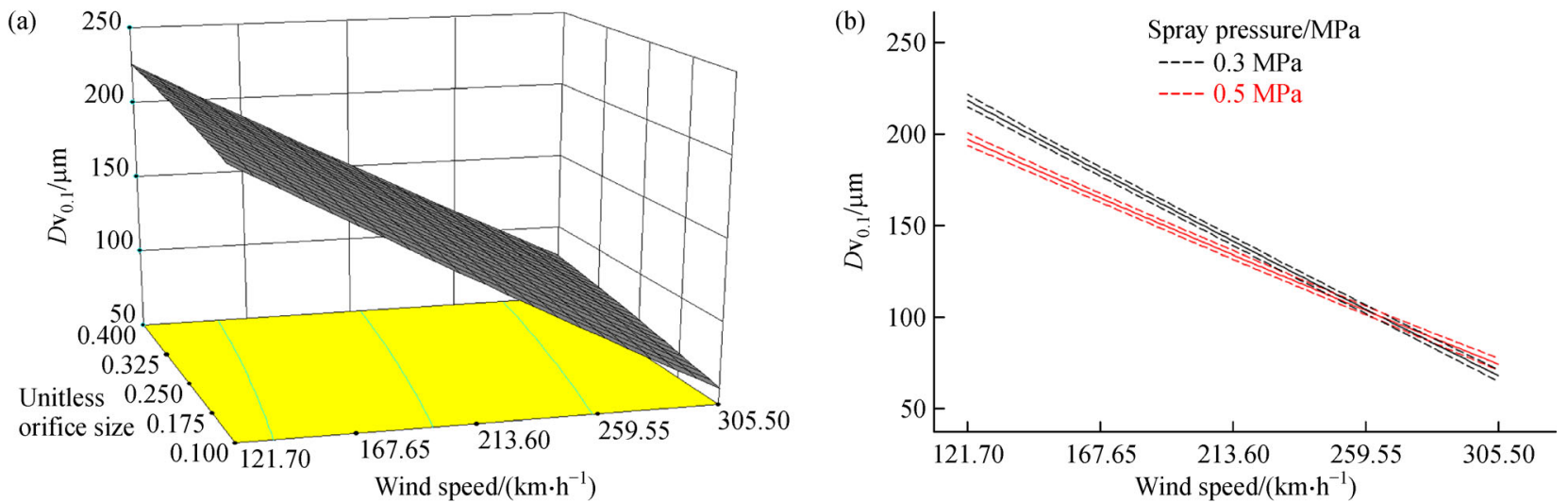

Fig. 7 3D response surface of $D \mathrm{v}_{0.1}$ related to the wind speed and orifice size (a) and the effect of the spray pressure and wind speed on $D \mathrm{v}_{0.1}$ (b)

The maximum diameter of droplets in shear flow was determined by the equation ${ }^{[33]}$ below:

$$
D_{\max }=\frac{W e \sigma_{l}}{\rho_{g} \Delta U^{2}}
$$

We is the Weber number, which depends on the breakdown conditions of the droplet. When bag breakup (one of the most important breakup modes) occurs, multiple studies ${ }^{[34]}$ have shown that $W e \approx 11 . D_{\max }$ is the maximum stable diameter of the droplet; $\rho_{g}$ is the air density; $\Delta U$ is the speed difference between the air and the liquid; $\sigma_{l}$ is the surface tension coefficient of the droplet.

From the above equation, it can be seen that the maximum stable diameter of the droplet was inversely proportional to the quadratic of the speed difference between the air and the liquid, which can influence $D \mathrm{v}_{0.9}$ to a certain extent.

$\%<100 \mu \mathrm{m}$ was found only quadratically related to wind speed and not markedly influenced by spray pressure and orifice size, as shown in Fig. 9.

The simplified formula is:

$$
\%<100 \mu \mathrm{m}=23.29-0.28 X_{1}+8.88 \times 10^{-4} X_{1}^{2}
$$

Since $\%<100 \mu \mathrm{m}$ is one of the primary parameters indicative of spray drift propensity of aerial applied agricultural materials, the equation indicates that changing spray pressure or nozzle orifice size had limited effect on reducing potential drift losses of small droplets.

$\%<200 \mu \mathrm{m}$ was similar to $\%<100 \mu \mathrm{m}$. It was not only influenced by wind speed, but also slightly influenced by nozzle orifice size, as shown in Fig. 10.

The simplified formula is:

$$
\begin{aligned}
\%<200 \mu \mathrm{m}= & 29.65-0.31 X_{1}-23.98 X_{3} \\
& +1.50 \times 10^{-3} X_{1}^{2}
\end{aligned}
$$

While $\%<200 \mu \mathrm{m}$ also provides a measure of potential spray drift from aerial sprays. The result indicated that increasing nozzle orifice size can slightly reduce $\%<$ $200 \mu \mathrm{m}$ and improve drift losses of larger droplets.

Because the common aerial spray application speed of the fixed-wing aircraft is about $150-260 \mathrm{~km} \cdot \mathrm{h}^{-1}$ (the working speed of Thrush $510 \mathrm{G}$ is about $150-240 \mathrm{~km} \cdot \mathrm{h}^{-1}$, and the Air Tractor $802 \mathrm{~A}$ is about $210-260 \mathrm{~km} \cdot \mathrm{h}^{-1}$ ), the $D \mathrm{v}_{0.5}$ of the droplet generated by the IDK nozzles at this speed range could be kept to $224-330 \mu \mathrm{m}$, which is an 

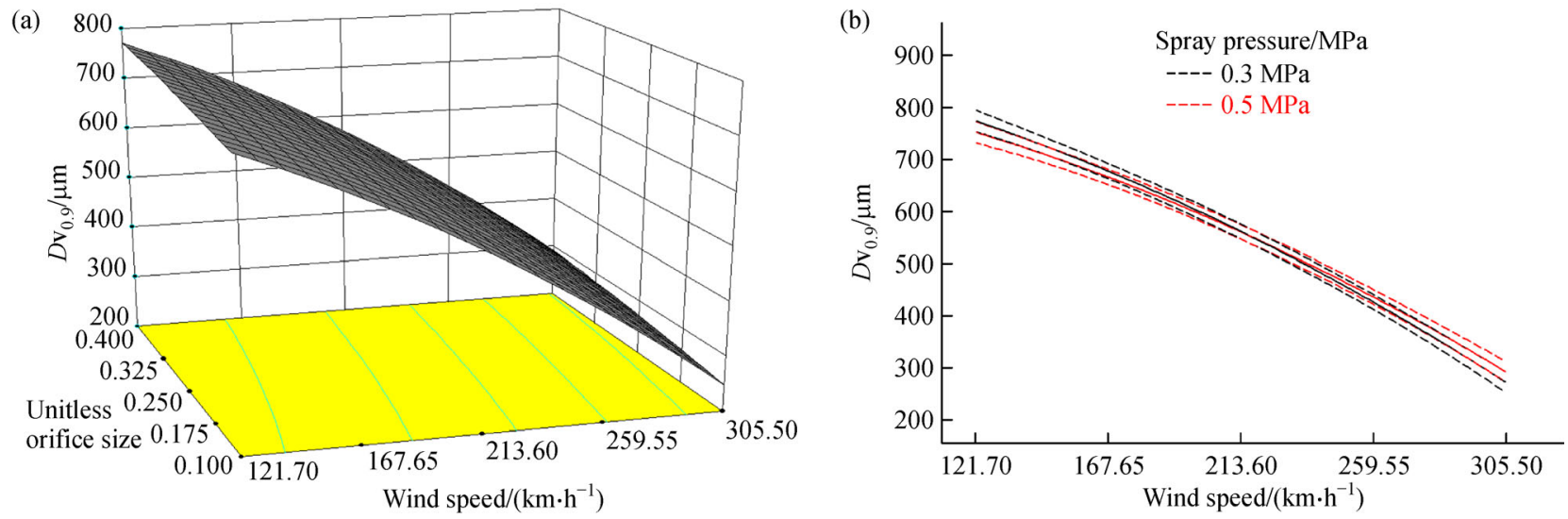

Fig. $83 \mathrm{D}$ response surface of $D \mathrm{v}_{0.9}$ related to the wind speed and orifice size (a) and the effect of the spray pressure and wind speed on $D \mathrm{v}_{0.9}$ (b)

(a)

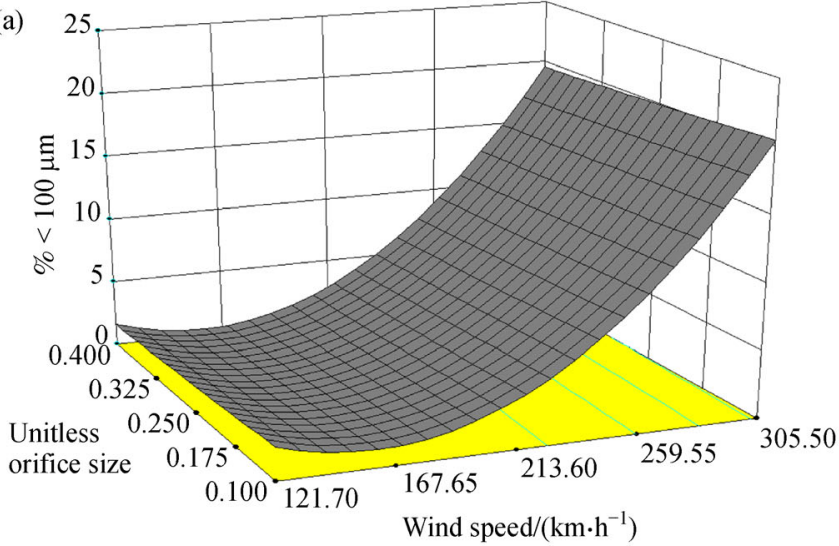

(b)

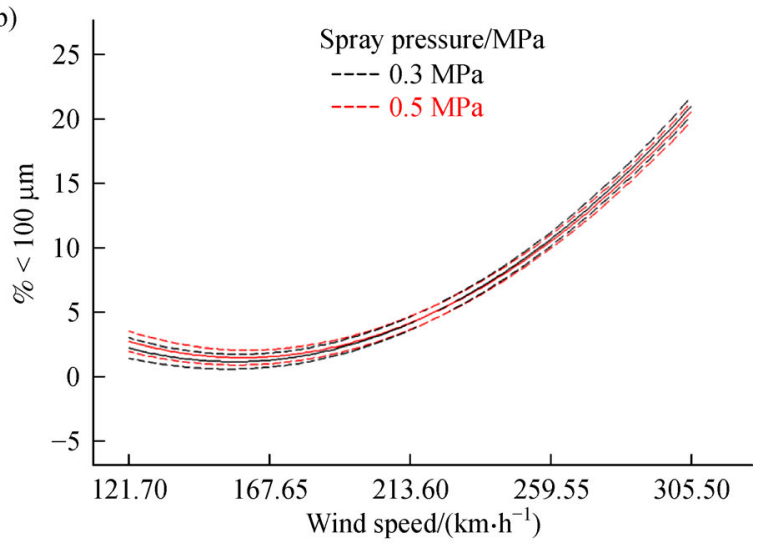

Fig. 9 The 3D response surface of the $\%<100 \mu \mathrm{m}$ related to the wind speed and orifice size (a) and the effect of the spray pressure and wind speed on the $\%<100 \mu \mathrm{m}$ (b)

(a)

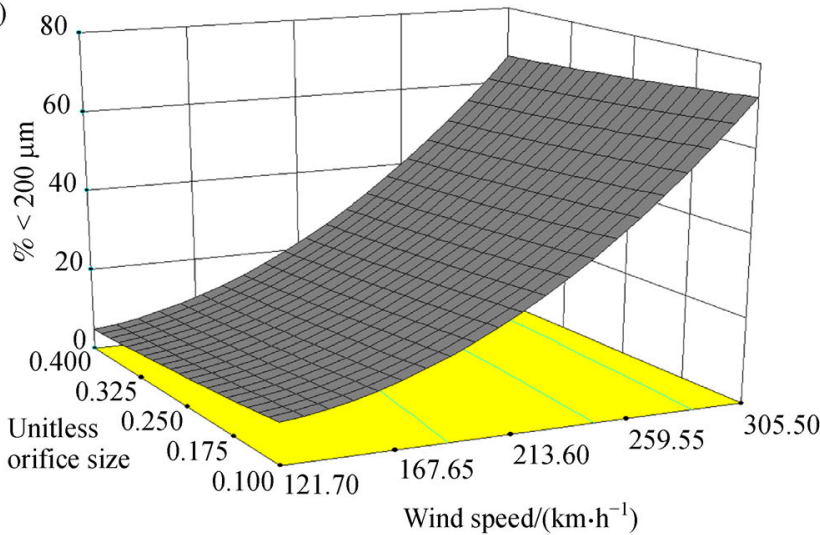

(b)

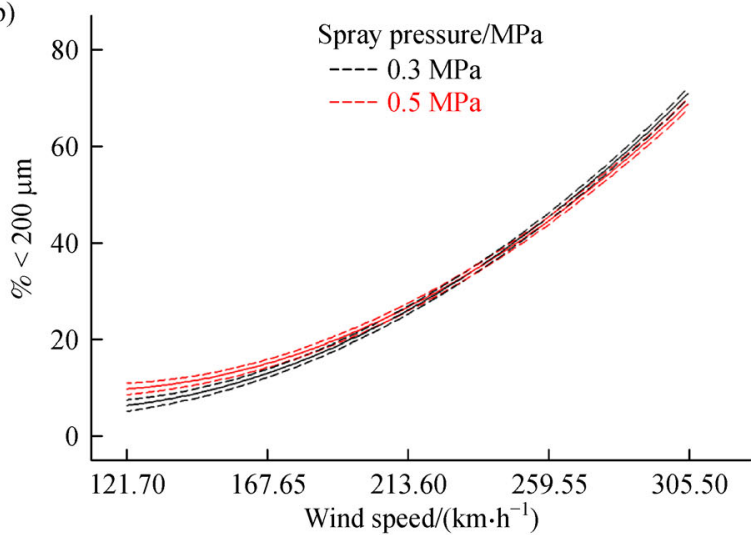

Fig. 10 The 3D response surface of the $\%<200 \mu \mathrm{m}$ related to the wind speed and orifice size (a) and the effect of the spray pressure and wind speed on the $\%<200 \mu \mathrm{m}(\mathrm{b})$ 
optimal size for weeding. Increasing nozzle orifice size could greatly increase the flow rate and improve drift losses of droplets with diameter between $100 \mu \mathrm{m}$ and $200 \mu \mathrm{m}$.

Based on these results, it could be suggested that the IDK nozzle is applicable for fixed-wing aerial spray weed control. Higher spray pressure and larger orifice size should be chosen to increase the flow rate and improve drift losses of the droplets at a high application speed. For example, when the spray pressure is $0.5 \mathrm{MPa}$ and the IDK120-04 nozzles have been used in an Air Tractor 802A with application speed of $260 \mathrm{~km} \cdot \mathrm{h}^{-1}$, the $D \mathrm{v}_{0.5}$ of the droplet is about $224 \mu \mathrm{m}, \%<200 \mu \mathrm{m}$ is $37.34 \%$ and $\%<100 \mu \mathrm{m}$ is $5.26 \%$. The potential drift losses of the IDK nozzles are still acceptable. Since the IDK nozzles with even larger orifice size (IDK-120-05 to IDK-120-08) were not tested in this paper, but it is believed that the IDK nozzle could perform well at high speed weeding condition. In contrast, in order to improve untargeted deposit losses of the droplets at a low application speed, higher spray pressure and smaller orifice size should be chosen. For example, when the spray pressure is set at $0.5 \mathrm{MPa}$ and the IDK-12001 nozzles have been used in a Thrush $510 \mathrm{G}$ with application speed of $150 \mathrm{~km} \cdot \mathrm{h}^{-1}$, the $D \mathrm{v}_{0.5}$ of the droplet is kept to about $330 \mu \mathrm{m}, \%<200 \mu \mathrm{m}$ is $18.25 \%$ and $\%<100 \mu \mathrm{m}$ is $2.5 \%$.

\section{Conclusions}

This paper tested a series of air induction nozzles at the IEA-I high-speed wind tunnel in NRCIEA. The parameters influencing the droplets distribution, including the wind speed, spray pressure and orifice size have been carefully studied. It was concluded that:

(1) Distance from the measuring point to the nozzle orifice greatly affected the distribution of the droplets. When the measuring point was $0.15 \mathrm{~m}$ from the nozzle orifice, the droplets, especially the large ones generated by the nozzle, were not fully atomized. When the measuring points were 0.25 and $0.35 \mathrm{~m}$ distant, the atomization of the droplets improved greatly, which indicates $0.35 \mathrm{~m}$ was a suitable measuring distance based on the size of the wind tunnel exit. The measuring distance should not be too far downstream from the nozzle, since the flow speed further downstream from the exit of the wind tunnel may be not uniform.

(2) Droplet size was found to be proportional to the orifice size, especially under low speed conditions. $D \mathrm{v}_{0.1}$ and $D v_{0.5}$ were inversely proportional to wind speed. Relatively, $D \mathrm{v}_{0.9}$ was influenced by the quadratic of the wind speed. Increasing the spray pressure slightly reduced droplet size under low speed conditions, and slightly increased droplet size under high speed conditions. However, the overall effect of spray pressure on droplet size was weak.
(3) $\%<200 \mu \mathrm{m}$ was found to be influenced by nozzle orifice size and the quadratic of the wind speed, the effect of the spray pressure was indistinct. However, the percentage of the small droplets which dominated the drift losses of small droplets, $\%<100 \mu \mathrm{m}$, was found to be largely independent of nozzle orifice size and spray pressure. This indicates that under high-speed operating conditions, reducing drift by increasing orifice size of the air induction nozzle or reducing the spray pressure are not suitable approaches.

(4) IDK nozzles could be used for aerial spray weeding, as the $D \mathrm{v}_{0.5}$ of the droplets is in the range of $224-330 \mu \mathrm{m}$, at an application speed of $150 \mathrm{~km} \cdot \mathrm{h}^{-1}$ to $260 \mathrm{~km} \cdot \mathrm{h}^{-1}$. At an application speed of $150 \mathrm{~km} \cdot \mathrm{h}^{-1}$, a spray pressure of $0.5 \mathrm{MPa}$ and the IDK-120-01 nozzle should be chosen to improve untargeted deposit losses of the droplets, and the $D \mathrm{v}_{0.5}$ of the droplet could be kept at about $330 \mu \mathrm{m}$. At an application speed of $260 \mathrm{~km} \cdot \mathrm{h}^{-1}$, a spray pressure of $0.5 \mathrm{MPa}$ and the IDK-120-04 nozzle should be chosen to improve drift losses of the droplets, and the $D \mathrm{v}_{0.5}$ of the droplet should be kept to about $224 \mu \mathrm{m}$.

Acknowledgements This work was supported by the National Natural Science Foundation of China (31601228, 31701315), the Youth Science Fund of the Beijing Natural Science Foundation (6164032), the Youth Science Fund of Beijing Academy of Agriculture and Forestry Sciences (QNJJ201631), and Beijing Talent Program for Ruirui Zhang.

Compliance with ethics guidelines Qing Tang, Liping Chen, Ruirui Zhang, Min Xu, Gang Xu, Tongchuan Yi, and Bin Zhang declare that they have no conflicts of interest or financial conflicts to disclose.

This article does not contain any studies with human or animal subjects performed by any of the authors.

\section{References}

1. Zhou Z, Zang Y, Luo X, Lan Y, Xue X. Technology innovation development strategy on agricultural aviation industry for plant protection in China. Transactions of the Chinese Society of Agricultural Engineering, 2013, 29(24): 1-10 (in Chinese)

2. Metcalf R L. Changing role of insecticides in crop protection. Annual Review of Entomology, 1980, 25(1): 219-256

3. Rice P J, Rice P J, Arthur E L, Barefoot A C. Advances in pesticide environmental fate and exposure assessments. Journal of Agricultural and Food Chemistry, 2007, 55(14): 5367-5376

4. Yates W E, Cowden R E, Akesson N B. Drop size spectra from nozzles in high-speed airstreams. Transactions of the ASAE: American Society of Agricultural Engineers, 1985, 28(2): 405-410

5. Akesson N B, Gibbs R E. Pesticide drop size as a function of spray atomizers and liquid formulations. In: Bode L E, Hazen J L, Chasin D G, eds. Pesticide formulations and application systems: tenth volume. Philadelphia: ASTM, 1990, 170-183

6. Bouse L F. Effect of nozzle type and operation on spray droplet size. Transactions of the ASAE: American Society of Agricultural Engineers, 1994, 37(5): 1389-1400

7. Standards A S A E. S572. Spray nozzle classification by droplet spectra. St. Joseph: ASAE, 2004 
8. Kirk I W. Measurement and prediction of atomization parameters from fixed-wing aircraft spray nozzles. Transactions of the ASABE, 2007, 50(3): 693-703

9. Miller P C H, Butler Ellis M C. Effects of formulation on spray nozzle performance for applications from ground-based boom sprayers. Crop Protection, 2000, 19(8-10): 609-615

10. Nuyttens D, Baetens K, De Schampheleire M, Sonck B. Effect of nozzle type, size, and pressure on spray droplet characteristics. Biosystems Engineering, 2007, 97(3): 333-345

11. Hewitt A J, Johnson D R, Fish J D, Hermansky C G, Valcore D L. Development of the spray drift task force database for aerial applications. Environmental Toxicology and Chemistry, 2002, 21 (3): 648-658

12. Hewitt A J. Droplet size spectra classification categories in aerial application scenarios. Crop Protection, 2008, 27(9): 1284-1288

13. Hoffmann W C, Fritz B K, Lan Y, Zollinger R, Rhode A, Dean S W. Evaluation of a proposed drift reduction technology high-speed wind tunnel testing protocol. Journal of ASTM International, 2009, 6(4): $1-10$

14. Fritz B K, Hoffmann W C, Bagley W E. Effects of spray mixtures on droplet size under aerial application conditions and implications on drift.Transactions of the ASAE: American Society of Agricultural Engineers , 2009, 26(1): 21-29

15. Fritz B K, Hoffmann W C, Kruger G R, Henry R S, Hewitt A J, Czaczyk Z. Comparison of drop size data from ground and aerial nozzles at three testing laboratories. Atomization and Sprays, 2014, 24(2): 181-192

16. Fritz B K, Hoffmann W C. Update to the USDA-ARS fixed-wing spray nozzle models. Transactions of the ASABE, 2015, 58(2): 281295

17. Derksen R C, Ozkan H E, Fox R D, Brazee R D. Droplet spectra and wind tunnel evaluation of venturi and pre-orifice nozzles. Transactions of the ASAE: American Society of Agricultural Engineers, 1999, 42(6): 1573-1580

18. Powell E S, Orson J H, Miller P C H, Kudsk P, Mathiassen S. Defining the size of target for air induction nozzles. In: BCPC International Congress- Crop Science \& Technology 2003, Glasgow. Hampshire: $B C P C, 2003,267-272$

19. Lafferty C L, Tian L F. The impacts of pre-orifice and air-inlet design features on nozzle performance. In: ASAE Annual International Meeting 2001, Sacramento. St. Joseph: ASAE, 2001, No. 011079

20. Ellis M C B, Swan T, Miller P C H, Waddelow S, Bradley A, Tuck C R. Design factors affecting spray characteristics and drift performance of air induction nozzles. Biosystems Engineering, 2002, 82 (3): 289-296
21. Vallet A, Tinet C. Characteristics of droplets from single and twin jet air induction nozzles: a preliminary investigation. Crop Protection, 2013, 48(2): 63-68

22. Berger-Neto A, Jaccoud-Filho D D S, Wutzki C R, Tullio H E, Pierre M L C, Manfron F, Justino A. Effect of spray droplet size, spray volume and fungicide on the control of white mold in soybeans. Crop Protection, 2017, 92: 190-197

23. Guler H, Zhu H, Ozkan H E, Derksen R C, Yu Y, Krause C R. Spray characteristics and drift reduction potential with air induction and conventional flat-fan nozzles. Transactions of the ASABE, 2007, $\mathbf{5 0}$ (3): 745-754

24. Dorr G J, Hewitt A J, Adkins S W, Hanan J, Zhang H, Noller B. A comparison of initial spray characteristics produced by agricultural nozzles. Crop Protection, 2013, 53(11): 109-117

25. Tang Q, Chen L, Zhang R, Zhang B, Yi T, Xu M, Xu G. Atomization characteristics of normal flat fan nozzle and air induction nozzle under high speed airflow conditions. Transactions of the Chinese Society of Agricultural Engineering, 2016, 32(22): 121-128 (in Chinese)

26. Tang Q, Chen L, Zhang R, Xu M, Xu G, Zhang B. Design and test of IEA I high speed wind tunnel for aerial plant protection. Transactions of the Chinese Society of Agricultural Engineering, 2016, 32(6): 73-81 (in Chinese)

27. Dodge L G, Rhodes D J, Reitz R D. Drop-size measurement techniques for sprays: comparison of Malvern laser-diffraction and Aerometrics phase/Doppler. Applied Optics, 1987, 26(11): 21442154

28. Hoffmann W C, Fritz B K, Bagley W E, Lan Y, Devisetty B, Dean S W. Effects of air speed and liquid temperature on droplet size. Journal of ASTM International, 2011, 8(4): 103461

29. ISO 10625.Equipment for Crop Protection. Sprayer Nozzles. Colour Coding for Identification. Geneva: International Organization for Standardization, 2005

30. Dombrowski N, Johns W R. The aerodynamic instability and disintegration of viscous liquid sheets. Chemical Engineering Science, 1963, 18(3): 203-214

31. Dombrowski N, Hooper P C. The effect of ambient density on drop formation in sprays. Chemical Engineering Science, 1962, 17(4): 291-305

32. Fraser R P, Eisenklam P, Dombrowski N, Hasson D. Drop formation from rapidly moving liquid sheets. AIChE Journal: American Institute of Chemical Engineers, 1962, 8(5): 672-680

33. Ashgriz N. Handbook of atomization and sprays: theory and applications. Berlin: Springer, 2011

34. Guildenbecher D R, López-Rivera C, Sojka P E. Secondary atomization. Experiments in Fluids, 2009, 46(3): 371-402 